\title{
Creer en lo otro. Thanatos, eros y anamnesis en The Giver
}

\author{
The Giver | Phillip Noyce | 2014 \\ Diego Fonti* \\ Universidad Católica de Córdoba \\ Pamela Cáceres \\ Universidad Católica de Córdoba
}

Recibido 2 de julio de 2019; aprobado 19 de febrero de 2020

\begin{abstract}
Resumen
A partir de la novela y el film The Giver, este artículo expone la paradoja y contradicciones que se que dan en el intento de una posición igualitaria y pacifista -respuesta clásica ante las discriminaciones que originan dolor y violencia- por eliminar todo lo que sea fuente de distinción, y por ende de angustia. Se expone además cómo ese movimiento acabó eliminando la creencia en lo otro y al mismo tiempo la memoria de todo lo que había causado angustia en el pasado. En segundo lugar, este artículo argumenta que en nombre de la igualdad lograda por la eliminación de la violencia nacida de la diferencia, se genera una violencia todavía más grave. Y que la eliminación social de la muerte y el deseo, como señales de esa memoria y eventos fundamentales de la experiencia humana, no contribuyeron a subsanar el desgarro sino a instaurar un daño más allá del límite. El argumento señala que la producción de seres humanos neutros, sin culpas pasadas ni angustias futuras, sin diferencias individuales significativas, no conlleva una vida más libre, fraterna e igualitaria, sino un tipo de violencia intrínseca y desbordada. Finalmente, se indagará la memoria de la diferencia y de la ley, en tanto rol del otro, como inicio de una apropiación subjetiva más completa.
\end{abstract}

Palabras Clave: igualdad | diferencia | otro | angustia | memoria

To believe in the other. Thanatos, eros and anamnesis in The Giver

\begin{abstract}
Based on the novel and the film The Giver, this papers shows the paradox and contradictions born out of the attempt of an egalitarian and pacifist position - the classical answer to those discriminations that originate suffering and violence - to eliminate everything that is a source of distinction and therefore of anguish. In the second place, we argue that in the name of an equality achieved by means of eliminating the violence born out of difference, a worse violence is originated. And that the social elimination of death and desire, as signals of that memory and fundamental events of human experience, did not contribute to heal that division but instead it set a damage beyond limits. The argument shows that a production of neutral human beings, without past guilt nor future anguish, withouth meaningful individual differences, does not bring about a life that is more free, fraternal and egalitarian, but an intrinsic and boundless sort of violence. Finally we will explore the memory of differenciation and of the law as role of the other and as starting point for a more complete subjective appropriation.
\end{abstract}

Keywords: equality | difference | other | anguish | memory

“La muerte es del ámbito de la fe. Ustedes tienen razón en creer que morirán, eso es lo que les sostiene. Si no lo creyesen, ¿podrían soportar la vida que tienen?” 1 J. Lacan, 13 de Octubre de 1972

No es infrecuente en la tarea académica abordar posiciones teóricas que total o parcialmente se enfrentan a las construcciones y enfoques propios. Ciertamente son desafíos que exigen respuesta, sea por medio de una refu- tación de la crítica o por la revisión de la propia posición. Sin embargo, es menos frecuente que una obra se afirme sobre los mismos principios y orientaciones que los propios, llevándoles -sin perder coherencia- hasta el punto cuya imagen se desfigura de tal modo que nos enfrenta al horror. Es más que la mera argucia lógica de la reducción al absurdo. Es un horror nacido inequívocamente de los propios principios y orientaciones que creíamos legítimo

* diegofonti@gmail.com 
-incluso un deber- sostener. Este tipo de conmoción es la que el film de 2014 The Giver (El dador de recuerdos, de Philip Noyce, basado en la novela homónima de Lois Lowry) nos provoca a quienes sostenemos una posición ética y políticamente igualitaria respecto de los seres humanos. Nos obliga a pensar las premisas mismas de esa posición y sus límites. Para este trabajo poco importa la calidad -o falta de ella- del film, sino otra cosa más intrigante: es forzar el reconocimiento de que nuestra propia posición política y ética contenía en su interior el huevo de la serpiente.

En este artículo se exponen, en primer lugar, los motivos por los cuales un argumento igualitario y pacifista -junto a la necesidad de enfrentar la violencia que históricamente los humanos hemos utilizado como respuesta a la diferencia, al dolor y a la muerte- llevó a aniquilar todo aquello que era fuente de distinción, y por ende de angustia. Lo central es que esa aniquilación significó también dejar de creer en lo otro. Además se muestra cómo junto con las fuentes de esa angustia se eliminó también toda memoria de las mismas. El argumento que se articula a partir de esta descripción es que en nombre de la eliminación de la violencia nacida de la diferencia y la alteridad, es decir, en nombre de la igualdad, se generó una violencia peor. Del mismo modo, la eliminación de la muerte y el deseo, así como las memorias y accesos a esos dos eventos fundamentales de la experiencia humana, no contribuyeron a subsanar el desgarro que conllevan sino a instaurar un daño más allá del límite. Ese daño no solo incide en las relaciones interhumanas sino que afecta la propia constitución de la subjetividad y la angustia que la acompaña. Así fue que la eliminación de la angustia que producían las características antropológicas ontológicamente insuperables de la experiencia humana, tales como el deseo y la muerte, no produjeron subjetividades más libres ni sociedades menos crueles. La producción de seres humanos neutros, limpios de culpas pasadas y angustias futuras, carentes de diferencias y propiedades individuales significativas, de seres humanos sin las dos mociones estructurales fundamentales de eros y thanatos, en síntesis, no significó una vida más libre, fraterna ni, en última instancia, igualitaria, sino un tipo de violencia intrínseca, tácita y desbordada, y por ende más difícil de resistir. Finalmente se indagará el rol de la memoria de la diferencia y la memoria de la ley, o sea del otro, como inicio de una posibilidad de apropiación subjetiva más completa.

\section{La utopía, o el lazo dominial acabado}

El inicio de The Giver nos ubica en una comunidad utópica, donde ha sido superada la confrontación que Miller (2005) formula entre la sociedad como "lazo dominial” y la idea de una sociedad como relación igualitaria. Con el objeto de superar las antiguas condiciones que generaban violencia entre los humanos, se ha logrado una sociedad sin desgarro ni anomalías inesperadas: control de la natalidad y equilibrio en el número de nacimiento y muerte de sus habitantes, control del clima, eliminación de todas las características personales y sociales que alguna vez portaron el germen del conflicto (diferencias de color de piel, diferencias económicas, disputas por el acceso a bienes o cargos en la sociedad, etc.), orden y asignación programada de los roles sociales de cada persona que ingresa a la adolescencia. También es una sociedad donde la muerte no está presente, es invisible, y se ha logrado por la mitad lo que Nietzsche (1995) esperaba en el apartado 278 de La gaya ciencia: por fin los hombres ya no piensan en la muerte; pero tampoco en la vida. Cuando los "ancianos" que detentan el poder determinan que el tiempo de alguien ha llegado, se le cuenta su vida (en el film de Noyce, se proyectan imágenes grabadas de su pasado), y los demás se despiden de quien será conducido al "otro lugar”. Incluso se adjudica un sentido a la más insignificante y repetitiva de las vidas, provocando paradojalmente un sentido generalizado de conformidad con el sentido (Lowry, 1993). Amor fati consumado. Y a continuación son "released", "liberados" (en la versión doblada "rehabilitados") "al otro lugar”, Elsewhere (Lowry, 199, p. 47). Lo mismo sucede con aquellos bebés que no crecen como es esperable, con aquellas personas que no se adaptan, y finalmente también con quienes meramente lo piden porque sienten que no encajan. Y de pronto ya no están más, sin que nadie sepa cómo sucedió. Esa "liberación" simplemente se da, se produce la ausencia sin el rigor de la partida ni la angustia que la antecede. Así el numerus clausus de la comunidad queda siempre estable -teniendo en cuenta que quienes cumplieron con el ciclo etario son despedidos hacia otro lugar- y saludable en tanto los sujetos anómalos también son despedidos.

Por ninguna parte aparecen los umbrales y límites de la vida. Ninguna carga violenta rompe su armonía. Del mismo modo, el uso de drogas que anulan la libido desde la adolescencia impide que emerjan los conflictos nacidos del deseo erótico. No está lo que pone en riesgo la vida, pero tampoco lo que la erotiza y la carga de deseo. 
En síntesis, una sociedad pacificada, donde la utopía ya no es un futuro que permanece futuro sino un presente consumado.

La imposición de una igualdad no sólo se ha concretado, sino que incluso ha borrado el origen de la diferencia. Aquello que Heidegger (1990) encontraba como inicio de la metafísica, y por ende de la tarea actual del pensar, o sea la noción originaria de diferencia (para Heidegger entre el ser y los entes), había logrado aquí su acabamiento social: la diferencia quedaba elidida y olvidada por una técnica social. Según Heidegger la esencia de la técnica no es algo técnico, sino un modo de darse el ser en nuestra época, que se caracteriza por poner a los entes a disposición, con un pensamiento calculador anticipante. Es una representación de la totalidad del mundo como mundo técnico, como cosa exclusiva del ser humano: los entes -incluido el ser humano mismo- vienen a nosotros en la forma de su planificación y cálculo (Heidegger, 1990). Lo notable en el mundo que Lowry describe, es que no sólo se calcula el futuro sino también el pasado: el riesgo de que reaparezca el mundo de diferencias y la violencia que le es propia queda conjurado por una economía del olvido. El olvido es programado, nada debe remitir a aquel mundo de diferencias, ni la música, ni los colores del mundo, ni mucho menos los hechos que irrumpieron y generaron los sentimientos más conmovedores: dolor, amor, odio, el sufrimiento por el hambre o el clima, etc. Las guerras, las crueldades, las discriminaciones, no sólo ya no existen, sino que se administra su amnesia. Pero además, quienes organizaron ese mundo utópico de planificación y cálculo en pos de la igualdad atendieron a una característica antropológica que resiste a toda programación, porque excede o antecede a cualquier constructivismo, es decir, sabían que lo otro reprimido permanece latente y puede reaparecer de modo ominoso en lo cotidiano, unheimlich. Por eso también instituyeron un antídoto funcional en la sociedad: el rol del dador de recuerdos.

Una vez al año se realiza en la comunidad utópica una asamblea que reúne a todos sus miembros: en la "ceremonia de los 12 años” (Lowry, 1993, p. 14) se asigna de por vida a cada joven miembro su tarea social. Del mismo modo que más adelante se asignan a los adultos sus núcleos familiares: las parejas y -eventualmente- los hijos asignados a cada pareja, reproducidos previamente de modo artificial, y gestados por "portadoras". Así quedan estables las funciones sociales "privadas" y "públicas". La pacificación igualitaria ha sido consumada.

Pero esa economía de un presente igualitario y de un olvido planificado requiere un anticuerpo. Porque la di- ferencia y la violencia que acarrea resiste todo intento de eliminación; porque nos es constitutiva. Por eso esa sociedad inventa un rol social único, exento del resto de las obligaciones, separado del resto: el dador de recuerdos. Lo que hace es recordar todo el mal, sentir en su cuerpo todo el dolor y el placer vividos en la historia de la humanidad, y sus violencias. El dador de recuerdos ve colores, escucha música, sufre todas las conmociones posibles que los humanos hemos conocido. Posiblemente siente amor y angustia. Pero su trabajo es mantener el sistema, y por eso cada vez que la comunidad pone en cuestión el orden lógico y sin diferencias imperante, les recuerda que hay algo ominoso y terrible que sucedió alguna vez, que ellos no pueden recordar ni nombrar, pero que debe ser evitado. El sistema provee de goce en la comodidad, evita que surjan sujetos en la conmoción de la violencia, y al mismo tiempo evita ver sus propios daños estructurales. ${ }^{2}$

Durante su ceremonia de doce años, el joven Jonas queda sin rol asignado. Luego, fuera de la mirada pública, se lo convoca como dador de recuerdos. Empieza su entrenamiento con el dador anciano y comienza a reconocer el sentido de algunos destellos que había tenido: colores, mociones interiores que él mismo sostiene al dejar de tomar las pastillas que controlaban su libido, y finalmente tiene la visión de su propio padre -un cuidador de bebés-administrando una inyección letal a un bebé que no tenía las condiciones de salud esperadas. Así comprende el sentido de la "liberación" en la comunidad perfecta, y qué significa ser enviado al otro lugar. También el dador de recuerdos le permite entender por qué su nombramiento no había sido en público. Es que al aproximarse al final del tiempo que le estaba previsto al anciano dador, los administradores de la sociedad perfecta ya habían designado una reemplazante en una asignación anterior en público. Pero ella sintió demasiada angustia ante la carga del pasado y ante el presente utópico acabado. Durante su entrenamiento vio, entre otras cosas, el tipo de carga que significaba esa sociedad pacificada: la relativización de las vidas personales respecto del cumplimiento de un estado de goce y comodidad, la creencia en el estado de cosas presente sin sujetos ni decisiones relevantes por hacer. Por eso ella pidió ser "liberada". Y como los administradores no podían permitirse nuevamente una designación pública que fracasase, no designaron a Jonas en público, y de hecho hicieron que la regla que permitía a todo ciudadano solicitar ser "liberado" ya no aplicara a los dadores de recuerdos. 


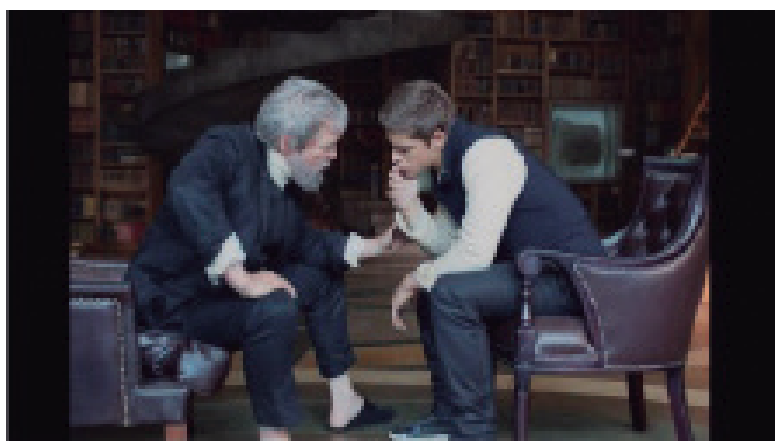

\section{La violencia ... o la violencia peor}

Jonas comienza a comprender la carga de violencia oculta que su sociedad utópica implica. Comprende que la sociedad ha domado las anomalías mediante la eliminación no sólo de las mociones básicas de angustia y deseo, sino que había pasado al acto en la eliminación concreta de los cuerpos. Ahora, animado por la memoria, comienza una resistencia contra ese orden total, como por ejemplo buscando liberar al bebé destinado a ser "liberado" por sus dificultades de crecimiento. Así, Jonas mismo se vuelve la anomalía que el cuerpo social utópico realizado quiere eliminar. Estos eventos nos muestran algo que va más allá de entender que la tecnociencia moderna puso fuera de juego las experiencias de muerte y eros, al tiempo que buscó reducir el traumatismo que implica el otro. Lo que en el fondo sucedió es que se renunció a ver lo "monstruoso" siempre presente en el otro, y la violencia que acecha, para negarle todo poder y someterle a una programación "normalizada", donde el otro finalmente es un calco de uno mismo. Paradojalmente, la negación de la violencia incurría en su absolutización, porque ya no hay diferencia entre violencias. La pacificación edulcorada y sin atributos, que niega toda violencia, termina sin distinguir entre sociedad existente y violencia, entre violencia y violencia.

Conviene confrontar esa "normalización" con los análisis sobre el "prójimo” de Žižek, que rompen no sólo con la idea humanista del vínculo con otro, sino también con la larga tradición del otro como alter ego. Esa idea todavía está presente en alguna interpretación posible del prójimo que es heredera del judeo cristianismo y se escucha, por ejemplo, en Rosenzweig y Levinas: “él es como tú”. Al revés, Žižek afirma que esa tradición judía y cristiana porta consigo un valioso "in-humanismo", necesario para esta época de la "muerte del sujeto" y del vínculo entre capitalismo y modos de reconoci- miento liberales marcados por el goce como mandato y por regulaciones, pero que no quiere pagar el precio ni admitir el tipo de violencia que signa todo encuentro con otro, y que por tanto no dan lugar a verdaderas decisiones éticas (Žižek 2009b, 169ss). Lo paradojal es que esa experiencia del otro, que tiene una estructura de corte religioso, es según Žižek lo que todavía da un acceso a lo "real" en la experiencia de la alteridad: no se trata de una representación imaginaria del otro como otro yo, ni de una instauración simbólica de la ley, sino del abismo brutal de lo real, que se sostiene ante otro.

Nuestra época logró prescindir del origen vertical y "carismático" -en términos weberianos- de la ley, intentando también normalizar mediante la razón nuestros impulsos (Žižek, 2001a). Pero la noción fuerte de prohibición ante y desde el otro manifiesta dos órdenes: el orden simbólico de la ley y el orden traumático de la alteridad. Según Žižek, es en el Moisés que Freud ve el doble vínculo entre la igualdad legal universal y el orden excepcional de su inicio con las dos figuras del padre. Lo decisivo es que hay un encuentro traumático que impide reducirlo todo al historicismo y a los acuerdos racionales en pos de ciertas equiparaciones. Las posiciones que niegan, racionalizan o pretenden superar el trauma, derivan finalmente en un goce sin límites ni sujetos. El goce que prefiere evitar los obstáculos que significarían su límite y su necesidad de responder de alguna manera ante el límite. Aparece una subordinación más cruel que la del reconocimiento del otro-fuente-de-violencia, que dominará toda la relación con el mundo y los demás, porque al rechazar esa excepción fundante de lo prohibido o demandado por otro, se priva de toda posibilidad de realidad (Žižek, 2005). En términos de Derrida: o es la violencia (del otro y de la ley), o es "lo peor". De allí que sea necesario admitir ese carácter traumático del otro, que según Žižek pasa desapercibido en autores como Levinas, para entender por qué lo que "lo que se resiste a la universalidad es la dimensión propiamente inhumana del prójimo", y por ende encontrarse a uno mismo en el otro es violento y traumático ya que "me hace sentir directamente la distancia entre lo que soy como ser determinado y la insondable $\mathrm{X}$ que hay en mí y que causa el amor" (Žižek, 2009a , p. 73). Caso contrario se acaba en lo peor de la sociedad "pacificada" pero sumida en la violencia peor: sin sujetos, sin otro, sin decisiones. Una sociedad "normalizada".

Esta sociedad "normalizada” corre el mismo riesgo que Derrida (2003b) encuentra en las expresiones sobre el "perdón" como medio para restablecer una normali- 
dad: allí hay algo que no es perdón ni responde a su concepto. Lo mismo con la violencia: cada vez que ella se utiliza como mecanismo en vistas de un fin, corre el riesgo de volverse la violencia "peor", aquella capaz de ser como una enfermedad autoinmune que acaba suicidando al cuerpo personal y social. Es la violencia "justificable". Por supuesto que este riesgo no es evitable: la violencia peor sucede cuando el otro -y uno mismo- queda totalmente apropiado a un determinado fin, totalmente cerrado sobre sí mismo. Pero aunque la violencia no sea evitable, sí parece posible deconstruir su origen, y ver su estructura a partir del vínculo con la alteridad, evitando así la violencia peor. Ese paso podría darse rompiendo el vínculo "justificable" con la violencia, desnudando las decisiones arbitrarias, mostrando su origen en un vínculo con lo otro.

Derrida vuelve sobre este análisis al estudiar la "religión" como re-ligar y re-leer. Ahí ve la doble posibilidad de cerrarse sobre sí y abrirse a lo otro (Derrida, 2003b). Así como Derrida busca definir el vínculo estructural en lo religioso previo a toda relación concreta con un Dios, del mismo modo hay que pensar lo que estructuralmente define a la violencia, previo a las formas y posibilidades concretas. Pensar en la violencia como lo que debe acompañar a la justicia para su concreción muestra todos los dilemas del caso: la necesidad en la justicia de una decisión finalmente arbitraria, el problema del cálculo entre cosas no equiparables, etc. En definitiva, la justicia permanece algo siempre insatisfecho, y creer que una determinada configuración cerró definitivamente el abismo es dejar de creer en lo otro y abrir paso a la violencia peor. Esto no significa abogar por el anarquismo o la negación de las instituciones, sino remitir al hueco que las funda y que ninguna sutura logra cerrar totalmente sin evitar, con esa certidumbre de sí, una violencia peor. Siempre resta lo indecidible, aun cuando haya que decidir.

El otro implica siempre una violencia porque reclama y busca imponerse. Sea el reclamo adecuado, sea una imposición inaceptable, siempre es un gesto de fuerza. Reconocerlo y saber esta estructura permite también reconocer los posibles derivados inaceptables: "solo la posibilidad infinita de lo peor y del perjurio es la que puede admitir la posibilidad del Bien, de la veracidad y de la fe jurada. Esta posibilidad permanece infinita, pero como la posibilidad misma de una finitud autoinmune" ${ }^{3}$ (Derrida, 2003a, p. 211). La justicia debe saber que puede volverse contra sí misma, al negar al otro de modo autoinmunitario. Para evitar el suicidio peor ha de hacerse lugar a las violencias del otro, por ejemplo a sus exigencias de no matarle y no dejarle solo en su mortalidad. ${ }^{4}$ En Voyous Derrida (2003a) piensa en eso incondicional que está más allá de la noción de soberanía, y le denomina "incondicional imposible" en Estados de ánimo del psicoanálisis: el don, la justicia, la hospitalidad, en fin, aquello que llamamos ética en un sentido radical. Aquello que nos abre a responder al otro.

\section{Los Otros-monstruos que acechan: el amor, la muerte, el prójimo}

En The Giver la igualdad no condujo a una mayor justicia, así como las técnicas empleadas para evitar que lo monstruoso en otro emerja sólo condujeron a una configuración social, en la que ya no hay separación entre lo monstruoso y la cruel buena conciencia vigente. Es el último eco del proceso que inicia con las diversas disciplinas de la modernidad, que nacen como un modo expreso de limitar la violencia. Ellas habían desmembrado la experiencia humana en diversas epistemes, y encuentran en todas ellas el miedo a la violencia y a la muerte como motor de acción. Hobbes es el ejemplo más acabado de este movimiento. Pero esa separación del ser humano en disciplinas y jurisdicciones finalmente acaba por poner fuera de juego a la muerte como experiencia subjetiva. Para prevenir la muerte ponen a la muerte fuera de juego. En su obra sobre Certeau, Mendiola analiza las similitudes estructurales de éste con Foucault, y luego resalta una gran diferencia: para el primero la muerte no llega de afuera, como una irrupción que rompe los órdenes, como sucede con Foucault, sino que ya está presente en el orden mismo. Para Certeau "El acto de creer es estar poseído por la muerte” (Mendiola, 2014, p. 52), porque lo inconmensurable no viene de afuera sino al interior de una taxonomía incluso cuando ésta todavía funciona. Creer significa recordar y aceptar lo que fue forcluido en las epistemes.

Ambos, Certeau y Foucault, hacen un diagnóstico paralelo sobre la modernidad y sus epistemes: las ciencias "humanas" surgen después del límite de la epistemología clásica del s. XVII, basada en la representación, cálculo y matematización del conocimiento, pero en las que no estaba "el hombre". En cambio, a partir del final del s. XVIII y el XIX la finitud humana pasa a ser la analítica que estructura los conocimientos y reconoce los propios límites de ella misma como representación. 
Este análisis, continúa Mendiola, lleva en su interior lo innombrable: la experiencia de la finitud y la muerte, que ya los místicos del s. XVI y XVII veían como el lugar de resistencia a los discursos que habían seccionado al ser humano en distintas jurisdicciones (Certeau, 1993). De allí la importancia que Certeau otorga al creer en lo otro: creer en la alteridad de la muerte, por ejemplo, permite reconfigurar cierta subjetividad que había quedado fragmentada en los discursos y técnicas modernas. Buscar aquello que al mismo tiempo fragmenta los saberes pero unifica la experiencia humana fragmentada significa hacer la "experiencia del límite", del lugar desde donde se ve: el cuerpo con su apertura al deseo y su sentido de finitud. Entonces no es casual que según Certeau psicoanálisis y mística compartan la búsqueda imposible de nombrar eso que quedó fuera de las ciencias modernas y su fragmentación de la experiencia humana: muerte y deseo. Su "objeto" escapa del ámbito de los objetos científicos, porque es una falla, una ausencia. Y la creencia en esa alteridad es mucho más que un acto concreto de fe, como el vinculado a las religiones particulares. Es producir una diferencia, reconocer la alteridad que se impone en ella, y hacer un contrato con ella (Mendiola, 2014). Por eso se entiende que los rituales que se ven en el film y en el libro de Lowry son sustitutos de esa producción de diferencia, porque reemplazan la violencia de la diferencia por repeticiones controladas -como sucede en tantas liturgias- para evitar la angustia del duelo y el impulso del erotismo. Pero así se instala una violencia peor, que en su "humanismo" por el otro concluye en la inhumanidad estructural.

Si el rito tradicionalmente era el ámbito de religación con lo otro y manifestación de la creencia en lo otro, en The Giver el rito se vuelve fin en sí precisamente para prevenir la creencia en lo otro y para certificar la condición presente, que ya no requiere creencias sino de simples constataciones. Por un lado, el lenguaje ritualizado es la expresión más plena del control sobre el lenguaje, la exactitud en la expresión que no da lugar a ambigüedades ni malentendidos. El rito "The evening telling of feelings" (Lowry, 1993, p. 4) exige de los miembros de la familia una precisión quirúrgica para nombrar lo que han sentido. Ese nombrar no sólo sirve para que se controlen los sentimientos $-\mathrm{y}$ eventualmente el poder actúe sobre ellos- sino que además lleva a desactivar la moción interna. Pero también el rito expone en público lo privado, como sucede en el ritual matutino de contar los sueños (Lowry, 1993). Las palabras deben representar con exactitud los estados de ánimo.

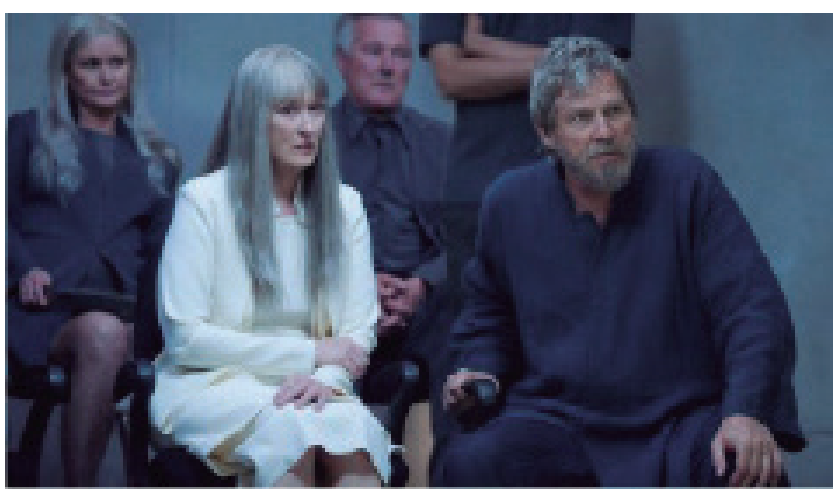

Los estados de ánimo o el temple anímico han sido desde Heidegger -aunque ya en Hegel- un punto de partida insoslayable para la filosofía. Se trata de un modo casi musical de afinar en un tono determinado al modo de ser del hombre, que marca de una determinada manera toda otra experiencia suya (Heidegger, 1997). Esta determinación no es una decisión subjetiva, sino que nace de la interrelación que determina la existencia, el ser en el mundo. No se trata aquí de elaborar una lista acabada de esos estados de ánimo, sino que sirve para mencionar cómo esta idea toma cuerpo en un discípulo de Heidegger, Otto Bollnow, para mostrar una tensión: ante el estado de angustia y embriaguez como estados de ánimo fundamentales y en tensión, Bollnow ofrece durante el “milagro alemán” de fines de los '50 un análisis de la Geborgenheit, o el sentimiento de seguridad. Esa especie de "fe en el ser", marcada por la confianza epocal optimista en un país en reconstrucción, como el sentimiento que supera la desprotección que la angustia hace sentir, fue criticada duramente por Adorno (2005) junto a toda la jerga de "autenticidad" heideggeriana. Ese conformismo y relación positiva con el ser goza -en lo que Adorno ve una estructura tomada de cierta fe religiosa- de un mundo en última instancia "sano", que por ende genera la "beatitud" en esa protección segura. Adorno llama "jerga" a un tipo de lenguaje que no combina los significantes sabiendo de su limitación y de su mutuo conflicto, lo que permitiría su uso crítico, sino que se busca una entificación cuasi sagrada en busca de ciertos efectos, como la función ideológica -potente y cómoda- que oculta el vacío.

Poner en un lenguaje definido los estados de ánimo y someterlos a una ideología del dominio y la seguridad, conllevó eliminar precisamente el estado de ánimo mismo. Como en las exigencias de expresión adecuada en The Giver, la excesiva preocupación por el uso definido del lenguaje, por ej. en su capacidad de nombrar de modo certero una emoción, sirven menos a la comprensión de lo sucedido que a su neutralización. De ese 
modo, tanto la "autenticidad" criticada por Adorno a Heidegger, como los intentos de algunos filósofos analíticos de fijar contenidos de modo estable, conducen a obturar el potencial crítico del lenguaje y su relación con la realidad. Esto nos devuelve a la obra de Lowry y al film de Noyce: la definición y claridad en la expresión acaba quitando las tensiones que los estados de ánimo permiten, asegurando una protección que evita el contacto con el sentimiento erótico o la angustia y el duelo.

\section{Anamnesis, ¿̨corriendo, enmascarando el fin?}

Casi al inicio de "La máquina de ser feliz", García nos pone in medias res del problema que nos convoca: diseñamos una máquina de ser felices para contribuir a evitar la angustia de recordar el fin. ${ }^{5}$ Es una máquina neutral, "no tiene que hacer bien, no tiene que hacer mal, es inocencia artificial". La máquina puede ser la sociedad utópica de Lowry, las diversas versiones de las religiones descarnadas, las sistematizaciones informáticas o neurocientíficas de la vida, todo aquello que evita la vuelta sobre la propia finitud y lo que genera en nuestra subjetividad. Lidiar con la angustia fue el objetivo de muchas cosmovisiones, incluida una larga tradición filosófica que busca eliminarla y que Rosenzweig (1997) sintetiza en el idealismo:

Por la muerte, por el miedo a la muerte empieza el conocimiento del Todo. De derribar la angustia de lo terrenal, de quitarle a la muerte su aguijón venenoso y su aliento de pestilencia al Hades, se jacta la filosofía. Todo lo mortal vive en la angustia de la muerte; cada nuevo nacimiento aumenta en una las razones de la angustia, porque aumenta lo mortal. Pare sin cesar el seno de la infatigable Tierra, y todos sus partos son puestos a la merced de la muerte: todos aguardan con temor y temblor el día de su viaje a lo oscuro. Pero la filosofía niega las angustias de la Tierra. (p. 43)

El miedo lleva al conocimiento, pero ese conocimiento tiene a menudo la finalidad de eliminar miedo y angustia, al representar lo que hay como un todo cobijado bajo el concepto y el conocimiento sub specie aeternitatis. En cambio, hay otro tipo de conocimiento que se da al sostener la angustia. Heidegger entiende que la angustia ante la nada que asoma en el pensamiento de la muerte es precisamente lo que nos permite pensar el ser, existir, proyectar, cuidar. Así la angustia no es un paralizante sino un disparador, lo mismo que el deseo. Pero la sociedad dominal de la utopía igualitaria pretendió borrar el riesgo de esos disparadores mediante su olvido. ¿Acaso desenmascarar el fin, y recordar ese inicio, son sólo formas de romper la máscara de inocencia, o además desatan nuevamente la violencia contenida?

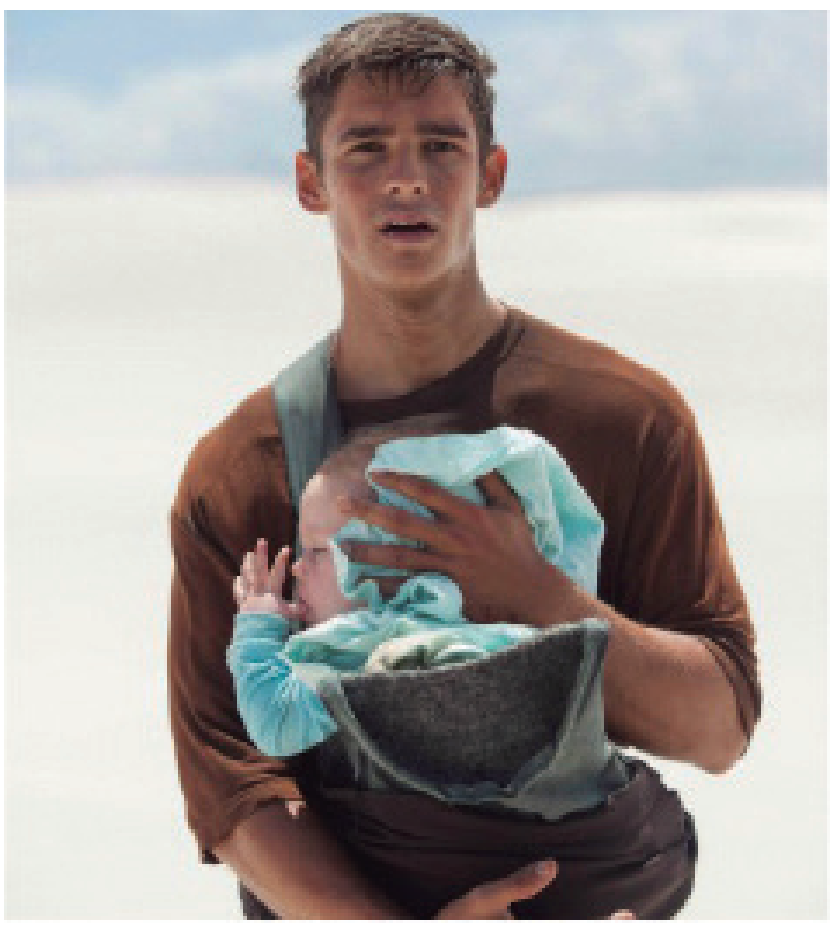

En la sociedad perfecta de El dador de recuerdos, después de la asignación de un futuro, la gente prácticamente perdía la conciencia del tiempo (Lowry, 1993). El proceso de identificación igualitaria es tan pronunciado que no hay ya ningún tipo de separación diferenciadora entre la sociedad y sus habitantes, entre una persona y las demás, entre sí mismo y los modos posibles de la temporalidad. Es que la conciencia del tiempo es esencialmente algo distinto de la contabilidad cronológica o de cuántas veces se repitió lo mismo. Los humanos somos efectivamente tiempo, pero también nos es constitutivo el hueco que separa nuestra subjetividad de la consumación temporal, ese vacío donde la identificación no es total y por ello podemos producirnos, transformarnos. Al mismo tiempo, es la conciencia de lo irrepetible en vistas de un fin que no se puede ya enmascarar, pero también es el recuerdo de lo que fue y lo que no fue, de lo que será y lo que no será. El tiempo es "tener tiempo" (Levinas, 1995, p. 59), es lo que "está después” (F. Cabrera), y por ende no sólo la angustia de la nada que acecha en el fin, sino también la tarea de hacer algo consigo en "el tiempo que queda” (S. Rennella), posiblemente diverso y más allá de la mera aceptación de lo vigente. El espacio abierto y la conciencia del fin introducen una diferencia, que al mismo tiempo nos es a todos igualmente estructural. 
Por lo tanto, toda búsqueda de justicia que atienda a esta igualdad y diferencia constitutivas tomará en cuenta los daños sufridos y los deseos truncos, para convertirse en testigo de ellos.

La memoria significa un modo de actualización que retiene y resignifica. De allí su rol revolucionario y conmovedor. Las dos tradiciones más influyentes en lo que llamamos occidente han portado su propia carga sobre la memoria, que puede reconstruirse en las discusiones entre Habermas y Metz. A partir de Benjamin, Metz (2007) afirma que el mundo griego no permite ver la memoria del sufrimiento, porque la memoria platónica es la memoria de un mundo ideal, eterno, perfecto. En cambio, la memoria del sufrimiento y la pasión, de todo aquello que horroriza la historia, se origina en el mesianismo judío y cristiano.

La tradición judía inicia otro modo de comprensión de la memoria. Es la memoria de los mandamientos, de la promesa y de los daños concretos. La propia tradición es la dadora -y mandante- universal de recuerdos. Es el mandato de recordar la ley, de sostener la promesa y de recordar el futuro y de recordar los sufrimientos vividos (Yerushalmi, 1982). Ahí se presenta la ley como límite posible a esa crueldad. El verbo zakar implica pensar lo sucedido y lo conocido, pero también la fidelidad al recuerdo. Tiene también una especie de dirección, porque significa recordar a favor de alguien (Thurian, 1965). Y al recordar, también quien recuerda se lo recuerda a otro. Todas estas formas de la memoria son una actualización del pasado, con toda su punción y tensión para quienes quieren mantener las formas.

Esa tradición se escucha hasta nuestro tiempo en voces como Levinas, Benjamin y Metz. Para Levinas (2009) la memoria es vinculación con lo otro, una "relación con lo que no se puede" (p. 102), a diferencia de las nociones de proyecto y poder. Es relación con un pasado que permanece pasado, que no se dio en un momento cronológicamente situado, ni por tanto se puede re-presentar (Levinas, 1987; 1995). Continuamente alterada, la memoria de lo ausente permanece. La vida psíquica, en tanto memoria, cumple y realiza un comienzo. Invierte, da vuelta, el tiempo; y al mismo tiempo lo invertido es un pasado que permanece siempre pasado. En el caso del otro, la memoria tiene un doble rol. En primera instancia es una memoria fenoménica. Como en el film, llegan al dador de recuerdos imágenes y sensaciones de todo aquello que la humanidad vivió, el estremecimiento de la caricia y el dolor del látigo, los colores de las flores y el sufrimiento de la guerra. Esos sufrimientos y place- res concretos traídos a la memoria, sin embargo, revelan algo "anterior". No cronológicamente anterior sino ontológicamente anterior. El encuentro con lo otro no se da en un momento fijable en el tiempo, por más que haya circunstancias particulares que elicitan la memoria del encuentro.

Habermas reconoce estos aportes pero afirma que ya la memoria griega en el marco del logos filosófico -la memoria en Platón- y su reconfiguración lingüística y comunicativa contemporánea busca un tipo de relación intersubjetiva íntegra de libertad, autonomía y respeto mutuo. Para él la memoria judeo-cristiana de la universalidad de la fraternidad y de la libertad ha sido un gran aporte al fusionarse con la tradición griega (Habermas, 2001). Además, la memoria funciona como mandato o postulado de una incondicionalidad que motiva y orienta a la crítica (Habermas, 2001). Habermas ve los aportes de integrantes de la primera Escuela de Frankfurt, como Benjamin y Horkheimer y una influencia judía: el ser humano es responsable por el mundo, pero al mismo tiempo sostiene un universalismo ético. Ambos aspectos deben recordar y actuar en función de una memoria concreta: "la injusticia ya sucedida y a todas luces irreversible", y el motivo es que hay una:

solidaridad entre los nacidos después y los que les han precedido, una solidaridad con todos los que por la mano del hombre han sido heridos alguna vez en su integridad corporal o personal; y que esa solidaridad sólo puede testimoniarse y generarse por la memoria. (Habermas, 1993, p. 26)

Más allá de sus tensiones y crisis, la tradición crítica de raigambre griega y el recuerdo del sufrimiento, del deber hacia otro y de la promesa, de origen hebreo, indican la distancia crítica del presente respecto del futuro "realizado". Esa distancia no se conoce en The Giver, aunque sí se ve allí el rol disruptor de la memoria que desdice al presente de su satisfacción y revela su violencia oculta. Con palabras de Rosenzweig (1997), "ninguna intervención en el mundo es sinónimo de o idéntica al "Reino", a la concreción utópica de la sociedad justa, sino que el "reino" siempre es futuro" (p. 406). Esto es un antídoto para cualquier afirmación de realización plena y no corregible. Al mismo tiempo implica una memoria de la necesaria transformación del mundo a la luz de otra memoria, del sufrimiento histórico. Es lo que Metz (2007) denomina "cultura anamnética" (p. 52), que recuerda el sufrimiento injusto e identifica en cada singularidad sufriente un mandato universal. En el caso de Metz es el contenido de la tradición bíblica, pero que puede 
extrapolarse a otras comprensiones del mundo, en tanto el sufrimiento y la demanda de liberación son una fuerza que rompe todo "apatismo" y ataraxia griega (Moltmann, 1975). La memoria es así el gran "lugar” desde donde juzgar la historia y las instituciones.

\section{Conclusión: Acerca de creer en lo otro}

El problema de lo otro y la creencia en lo otro manifiestan así su tensión en The Giver: por un lado, esa sociedad utópica no "cree" en eros y thanatos, porque toda experiencia que podría llevar a su manifestación ha sido ocluida. Pero eso no significó la eliminación de la creencia sino la construcción de una afirmación sin fisuras de lo que hay, el reemplazo idolátrico de la complejidad y la tensión por la afirmación inocente y peligrosa de una manifestación pacificada como totalidad de las experiencias posibles. Los conflictos y tensiones que genera la búsqueda siempre inacabada de la igualdad y la justicia fueron reemplazados por la instauración de un régimen simétrico y sin cualidades diferenciales.
Así, el problema de la creencia se manifiesta con una fuerza imparable. Lo otro no es "constatable", como exige el positivismo científico. Lo constatable no requiere de ninguna creencia. Lo insondable del otro sí. Ese abismo de lo real puede otearse en la angustia ante la muerte, en la conmoción del deseo, en el sufrimiento demandante de otro. El acicate de la memoria nos devuelve una y otra vez a esa creencia, no sólo para negar el determinismo y el acabamiento de las configuraciones sociales que hayamos hecho. También opera como estructura de nuestra subjetividad.

Finalmente, este recorrido nos devuelve a nuestro presente y las habituales exigencias de tolerancia, racionalismo y diálogo polite. Sin quitar el valor a los consensos y a la tolerancia, es preciso mantener el recuerdo del daño sufrido y las demandas del otro en toda su brutalidad, ya que la pacificación puede terminar siendo la eliminación del otro. Ese otro con quien compartimos los vacíos de la muerte, el amor y la vulnerabilidad, es decir, esos abismos que constituyen nuestra vulnerabilidad común y que son un punto de partida alternativo para pensar la justicia igualitaria.

\section{Referencias}

Adorno, Th.W. (2005). Dialéctica negativa; La jerga de la autenticidad. Akal.

Certeau, M. de (1993). La fábula mística. Ediciones Universidad Iberoamericana.

Derrida, J. (2003a). Voyous. Galilée.

Derrida, J. (2003b). El siglo y el perdón. Fe y saber. Ediciones de la Flor.

Habermas, J. (1993). El discurso filosófico de la modernidad. Taurus.

Habermas, J. (2001). Israel o Atenas. Trotta.

Heidegger, M. (1990). Identidad y diferencia. Anthropos.

Heidegger, M. (1997). Ser y tiempo. Editorial Universitaria.

Levinas, E. (1987). De otro modo que ser o más allá de la esencia. Sígueme.

Levinas, E. (1995). Totalidad e infinito. Sígueme.

Levinas, E. (2009). Parole et silence. Oeuvres 2. Grasset.

Lowry, L. (1993) The Giver. Houghton Mifflin.

Mendiola, A. (2014). Michel de Certeau: epistemología, erótica y duelo. Ediciones Navarra.

Metz, J.B. (2007). Memoria passionis. Una evocación provocadora en una sociedad pluralista. Sal Terrae.

Miller, J.A. (2005). La utilidad directa. Freudiana (43-44), pp. 7-30.

Moltmann, J. (1975). El Dios crucificado. Sígueme.

Nietzsche, F. (1995)[1882]. La gaya ciencia. ME Editores.

Noyce, P. (2014). The Giver [película]. Walden Media y The Weinstein Company.

Rosenzweig, F. (1997). La Estrella de la Redención. Sígueme.

Thurian, M. (1965). La eucaristía. Sígueme.

Yerushalmi, Y. (1982). Zakhor. Jewish History and Jewish Memory. University of Washington Press. 
Žižek, S. (2005). El títere y el enano. El núcleo perverso del cristianismo. Paidós.

Žižek, S. (2009a). Sobre la violencia. Seis reflexiones marginales. Paidós.

Žižek, S. (2009b). El frágil absoluto o ¿por qué merece la pena luchar por el legado cristiano? Pre-Textos.

1 “La mort est du domaine de la foi. Vous avez bien raison de croire que vous allez mourir bien sûr; ça vous soutient. Si vous n’y croyez pas, est-ce que vous pourriez supporter la vie que vous avez?” (T. de los A.)

2 De todos modos, el chiste morboso cumple su función develadora de la verdad que se quiere ocultar: en la obra se narran pequeños momentos de ironía en los que alguien comete un error y los demás niños en forma de juego dicen que será "liberado" “al otro lado”.

3 “Seule la possibilité infinie du pire et du parjure peut accorder la possibilité du Bien, de la véracité et de la foi jurée. Cette possibilité reste infinie mais comme la possibilité même d'une finitude auto-immunitaire” (T. de los A.)

4 Este no es el lugar para una exégesis detallada de la noción de raíz levinasiana de relación con el rostro y la "no violencia” (o violencia) de la misma. Sí cabe acotar que el rostro está lejos de ser en Levinas una aparición de buenos modales que solicita entrar a una comunidad comunicativa simétrica, sino más bien -y en progresiva escalada en la obra levinasiana- la irrupción de una figura indeseable y demandante de sus necesidades básicas, ante todo no morir, ni por la muerte causada por otro ni por las carencias también causadas por otros. Por lo tanto si bien es cierto que hay una visión del prójimo que "es como tú", y del rostro como relación de paz, también está incluida una noción del traumatismo y del deseo de lo no deseable.

5 Las alusiones a músicos -García, Cabrera, Rennella- en este trabajo se remiten a conceptos de sus obras y no se consignan en las referencias. 